EUROPEAN CENTRAL BANK

WORKING PAPER SERIES

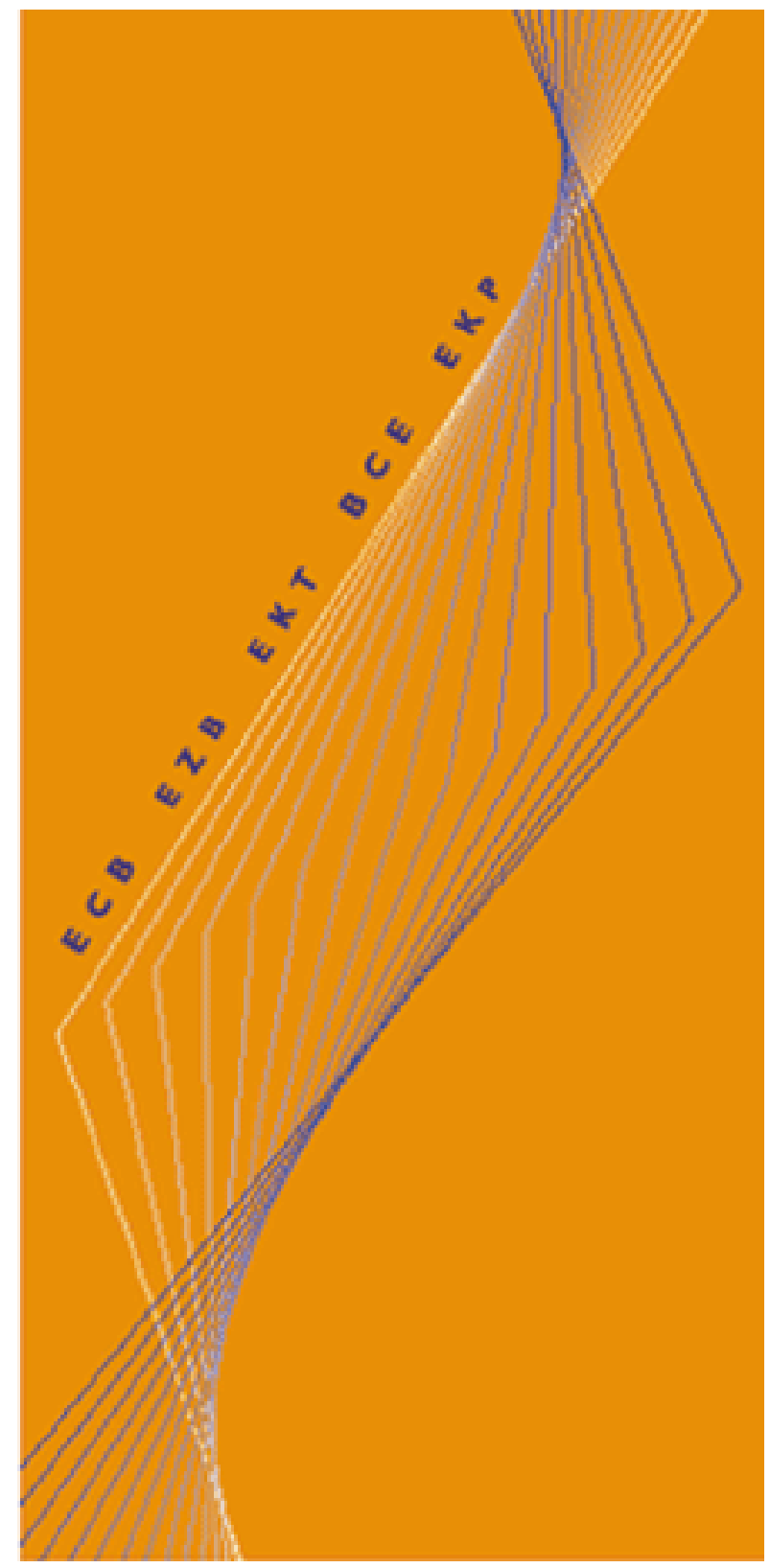

WORKING PAPER NO. I 94

SENSITIVITY ANALYSIS OF VOLATILITY: A NEW TOOL FOR RISK MANAGEMENT

BY SIMONE MANGANELLI, VLADIMIRO CECI AND WALTER VECCHIATO

November 2002 


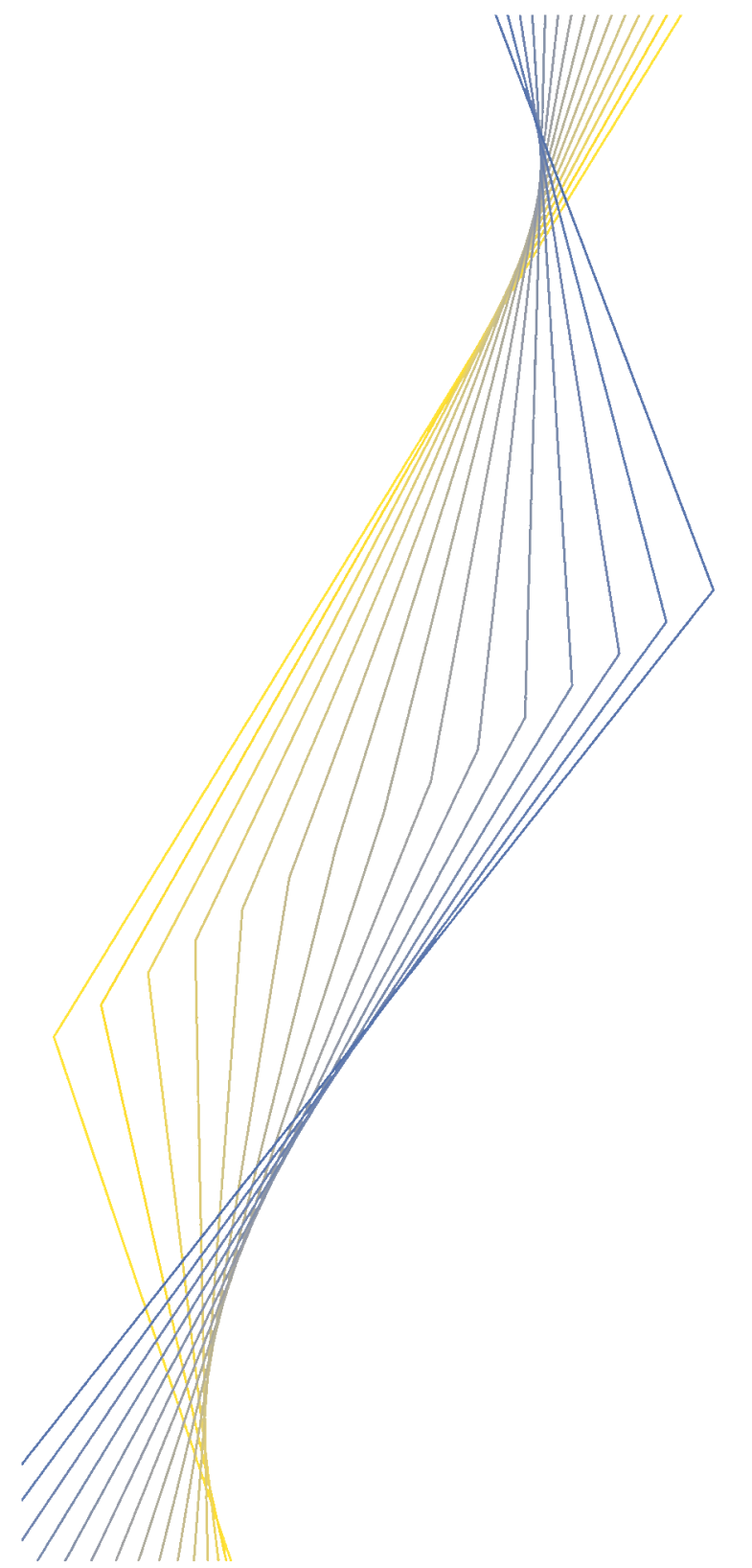

WORKING PAPER NO. I 94

\section{SENSITIVITY ANALYSIS OF VOLATILITY: A NEW TOOL FOR RISK MANAGEMENT'}

\section{BY SIMONE MANGANELLI', VLADIMIRO CECI AND ${ }^{3}$ WALTER VECCHIATO ${ }^{4}$}

\section{November 2002}

I We would like to thank Lutz Kilian, Neil Shephard, Kevin Sheppard and the Editorial Board of the ECB Working Paper Series, for useful comments and suggestions. Luca Lotti wrote the Matlab codes used for the estimation of the DCC and OGARCH multivariate models. The opinions expressed herein are those of the authors and do not necessarily represent those of the European Central Bank, IntesaBCl or Tradinglab.

2 European Central Bank, Kaiserstrasse 29, D-603 I I Frankfurt am Main, Germany, email: simone.manganell@ecb.int

3 Tradinglab Banca S.p.A., Corso Italia 3, I-20I 22 Milano, Italy, email: vladimiro.ceci@tradinglab.com

4 IntesaBCI, Risk Management Department,Via Clerici 4, I-20I 2 I Milano, Italy, email: vecchiato@opoipi.bancaintesa.it 
(C) European Central Bank, 2002

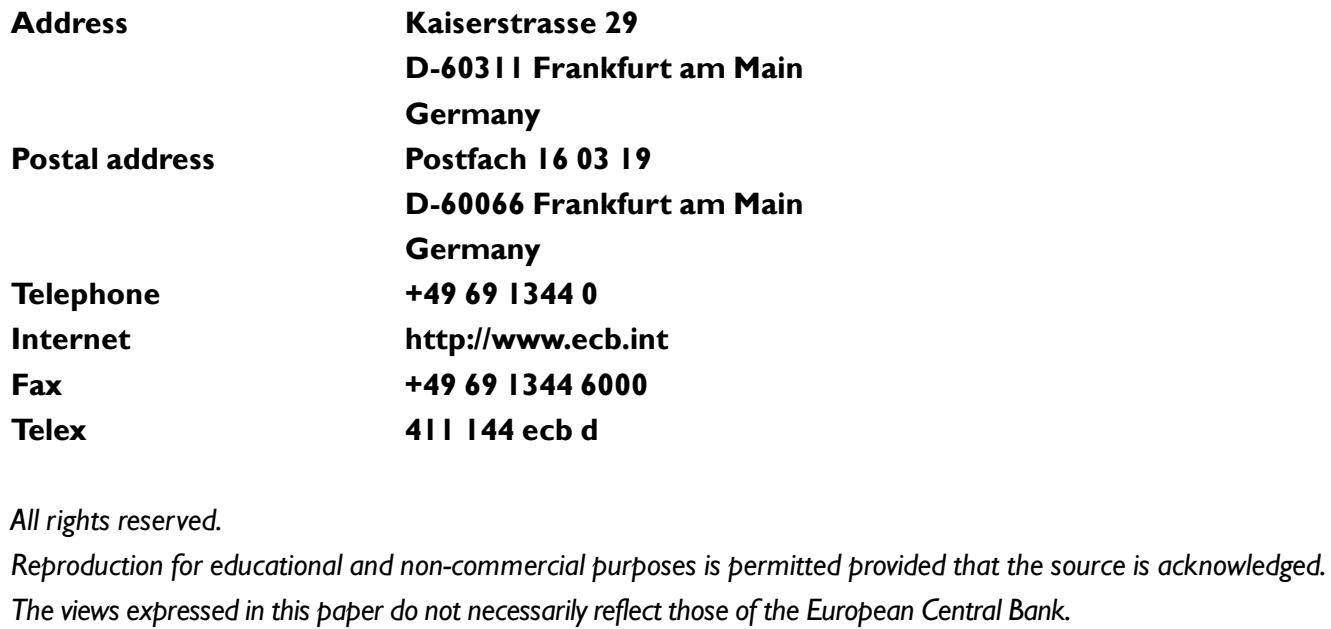

4 I I I 44 ecb d

Fax

Telex

All rights reserved.

Reproduction for educational and non-commercial purposes is permitted provided that the source is acknowledged. The views expressed in this paper do not necessarily reflect those of the European Central Bank.

ISSN $156 \mid-0810$ 


\section{Contents}

$\begin{array}{ll}\text { Abstract } & 4\end{array}$

Non-technical summary $\quad 5$

$\begin{array}{ll}\text { I. Introduction } & 6\end{array}$

2. Sensitivity analysis 9

$\begin{array}{ll}\text { 3. Sensitivity analysis correlations } & 13\end{array}$

4. Empirical application $\quad 17$

4.I Sensitivity of GARCH variance 18

4.2 Variance-Covariance estimation 2I

5. Conclusions 24

$\begin{array}{ll}\text { References } & 25\end{array}$

Figures \& Tables $\quad 27$

European Central Bank working paper series 33 


\begin{abstract}
The extension of GARCH models to the multivariate setting has been fraught with difficulties. In this paper, we suggest to work with univariate portfolio GARCH models. We show how the multivariate dimension of the portfolio allocation problem may be recovered from the univariate approach. The main tool we use is the "variance sensitivity analysis", which measures the change in the portfolio variance as a consequence of an infinitesimal change in the portfolio allocation. We derive the sensitivity of the univariate portfolio GARCH variance to the portfolio weights, by analytically computing the derivatives of the estimated GARCH variance with respect to these weights. We suggest a new and simple method to estimate full variance-covariance matrices of portfolio assets. An application to real data portfolios shows how to implement our methodology and compares its performance against that of selected popular alternatives.
\end{abstract}

JEL classification: C32, C53, G15

Keywords: Risk Management, Sensitivity Analysis, Dynamic Correlations, GARCH 


\section{Non technical summary}

Estimation of large multivariate volatility models is essential for risk management purposes. Such estimation, however, is notoriously challenging, mainly due to the fact that the number of parameters that need to be estimated increases exponentially, as one leaves the univariate domain. This paper suggests to look at the multivariate problem from a different perspective. We work with univariate portfolio models, and develop tools to recover the multivariate dimension that is lost in the univariate estimation. This is accomplished by recognising that the estimated univariate portfolio variance is a function of the weights of the assets that form the portfolio. By taking the derivatives of the variance with respect to these weights, it is possible to obtain information about the local behaviour (around the portfolio weights) of the estimated variance.

Our sensitivity measure has many interesting practical applications. To start with, risk managers might use our sensitivity analysis to test whether their actual portfolio has minimum variance. Indeed, the minimum variance portfolio will be characterised by having all first derivatives with respect to the portfolio weights equal to zero. The sensitivity analysis could also be used to evaluate the impact that each individual (or group of) asset has on the portfolio variance. This would help risk managers to find out what the major sources of risk are, or allow them to evaluate the impact on the portfolio variance of a certain transaction. A third application, proposed in this paper, is a new and simple method to estimate full variance-covariance matrices of portfolio assets. This is accomplished by exploiting the analytical relationship among variances, covariances and the variance derivatives with respect to the portfolio weights.

We illustrate the functioning and the performance of our methodology with two empirical applications. In the first one, we estimate the variance sensitivity for a portfolio of two assets. We document how this sensitivity has been changing over time and stress its implications for risk management. We also compute the second derivative of the estimated variance with respect to the portfolio weights. We argue that this measure gives an indication of the diversification opportunities at any given point in time: the higher this second derivative, the greater the gains (in terms of variance reduction) from a proper diversification strategy. In the second application, we implement the suggested methodology to estimate full variance-covariance matrices. We test the model with a sample of 10 stocks, taken from the Dow Jones index. We evaluate the performance of our methodology against that of popular alternatives. 


\section{INTRODUCTION}

Estimates of volatilities and correlations are used for pricing, asset allocation, risk management and hedging purposes. In today's fast changing financial world, it is essential that these measures are easy to understand and to implement. Since their introduction by Engle (1982), ARCH models have been used extensively both in academia and by practitioners to estimate the volatility of financial variables. Many papers have been written on the subject, extending the original ARCH model in many directions. The multivariate extension, however, has been met with many difficulties, mainly due to the fact that the number of parameters that need to be estimated increases exponentially, as one leaves the univariate domain.

This paper suggests to look at the multivariate problem from a different perspective. The key idea is to work with univariate portfolio models, and to develop tools to recover the multivariate dimension that is lost in the univariate estimation. This is accomplished by recognising that the estimated univariate portfolio variance is a function of the weights of the assets that form the portfolio. By taking the derivatives of the variance with respect to these weights, it is possible to obtain information about the local behaviour (around the portfolio weights) of the estimated variance.

Estimation of large multivariate GARCH models is notoriously challenging, requiring strong assumptions to make such estimation feasible. For instance, the most general multivariate GARCH model, the $\operatorname{GARCH}(1,1)$ vec representation introduced by Engle and Kroner (1995), requires the estimation of 21 parameters to obtain the variance-covariance matrix of just two assets. When the assets are five, there are 465 parameters to estimate and with ten assets the number of parameters raises to 6105 ! 
Moreover, restrictions need to be imposed on the variance-covariance matrix to ensure its positive definiteness. It is easy to argue that the high level of parameterisation and the assumptions on the structure of the variance-covariance matrix are likely to increase the dangers of misspecification and poor performance of the model.

On the other hand, the advantage of fitting variance models directly to the time series of portfolio returns is that they indirectly incorporate any time varying correlation among the assets. This makes it possible to estimate parsimonious models that summarise the relevant characteristics of the assets entering the portfolio. This is done, for example, by McNeil and Frey (2000) to calculate the Value at Risk of the portfolio. The drawback of this approach, however, is that the multivariate dimension of the portfolio allocation problem is lost. Given the estimated variance of a portfolio, a risk manager would be unable to determine how this variance changes as the portfolio composition evolves or to isolate the main sources of risk. It is not clear how to address these issues in an univariate framework. In the following pages, we suggest the use of sensitivity measures to overcome this problem.

Recently, measures of sensitivity to the weights of the portfolio allocation have been proposed for Value at Risk (VaR) models. Garman (1996) suggested to compute the derivative of the $\mathrm{VaR}$ with respect to the individual components of the portfolio, to assess the potential impact of a trade on a firm's VaR. Gourieroux, Laurent and Scaillet (2000) study the theoretical implication of this exercise on different VaR models. The same type of question can be asked with respect to the variance of a portfolio. When a full variance-covariance matrix is available, this is a straightforward exercise. But when univariate portfolio variances are estimated it is not obvious how to proceed. 
The main contribution of this paper is to show how to perform variance sensitivity analysis in the context of univariate GARCH models. We derive the sensitivity of the univariate portfolio GARCH variance to the portfolio weights, by analytically computing the derivatives of the estimated GARCH variance with respect to these weights. It is important to recognise that not only the portfolio returns, but also the estimated parameters of the GARCH model are function of the weights. We show how a simple application of the Implicit Function Theorem to the first order conditions of the log-likelihood maximisation problem can be used to overcome this obstacle.

Our sensitivity measure has many interesting practical applications. To start with, risk managers might use the GARCH sensitivity analysis to test whether their actual portfolio has minimum variance. Indeed, the minimum variance portfolio will be characterised by having all first derivatives with respect to the portfolio weights equal to zero. The GARCH sensitivity analysis could also be used to evaluate the impact that each individual (or group of) asset has on the portfolio variance. This would help risk managers to find out what the major sources of risk are, or allow them to evaluate the impact on the portfolio variance of a certain transaction. A third application, proposed in this paper, is a new and simple method to estimate full variance-covariance matrices of portfolio assets. This is accomplished by exploiting the analytical relationship among variances, covariances and the variance derivatives with respect to the portfolio weights. We show how a multivariate problem with $(n+1)$ assets collapses in $(n+1) n / 2$ univariate problems analytically connected.

The plan of the paper is the following. The next section illustrates our methodology. Section 3 shows how to employ GARCH sensitivity analysis to estimate 
full variance-covariance matrices. Section 4 contains an empirical application and section 5 concludes.

\section{SENSITIVITY ANALYSIS}

In this section, we show how to compute the derivative of the univariate GARCH portfolio variance with respect to the portfolio weights. Changing the portfolio weights changes the time series of portfolio returns, and thus changes the information set used in the estimation of the univariate GARCH model. As a consequence, the estimated variance is function of the portfolio weights, both through the vector of portfolio returns and through the estimated parameters (which obviously depend on the time series of portfolio returns used in estimation). Differentiation of the portfolio returns with respect to the portfolio weights is straightforward. To differentiate the estimated parameters we appeal to the Implicit Function Theorem. The idea is that, since the estimated parameters must satisfy the first order conditions of the log-likelihood maximisation problem, if certain continuity conditions are satisfied, the first-order conditions define an implicit function between the estimated parameters and the portfolio weights.

Let $y_{t}$ be the return of the portfolio $P$ composed by $n+1$ assets and let $y_{t, i}$ be the $i^{\text {th }}$ asset return, for $t=1, \ldots, T$ and $i=1, \ldots, n+1$. Indicating the weight of asset $i$ by $a_{i}$, the portfolio return at time $t$ is $y_{t}=\sum_{i=1}^{n+1} a_{i} y_{t, i}$. Note that since the weights $a_{i}$ have to sum to one, we can write one weight as a function of the others, $a_{n+1}=1-\sum_{i=1}^{n} a_{i}$. 
Assume that $y_{t}$ is modelled as a zero-mean ${ }^{1}$ process with a $\operatorname{GARCH}(p, q)$ conditional variance $h_{t}$ :

$$
\begin{array}{ll}
y_{t}=\sqrt{h_{t}} \varepsilon_{t} & \varepsilon_{t} \mid \Omega_{t} \sim(0,1) \\
h_{t}=z_{t}{ }^{\prime} \theta &
\end{array}
$$

where $\underset{m x 1}{z_{t}}=\left(1, y_{t-1}^{2}, \ldots, y_{t-q}^{2}, h_{t-1}, \ldots, h_{t-p}\right)^{\prime}, \underset{m x 1}{\theta}=\left(\alpha_{0}, \alpha_{1}, \ldots, \alpha_{q}, \beta_{1}, \ldots, \beta_{p}\right)^{\prime}$ and $m=p+q+1$. The information set of this model is $\Omega_{t}=\left\{a, y_{t, 1}, \ldots, y_{t, n+1}\right\}$, where $a$ denotes the $n$-vector of portfolio weights. ${ }^{2}$ Note that the information set includes the time series of the individual assets returns and that a change in the vector of portfolio weights implies a change in the information set. Therefore, to assess the potential impact of a trade on the estimated variance, one would have to re-estimate the whole model, given that $a$ and hence the information set has changed. The problem is that such a procedure would quickly become cumbersome and impractical, as the number of assets increases.

The potential effect of any change in the portfolio weights on the estimated variance could be evaluated by simply computing the first derivative of the variance with respect to the weights. A positive derivative would indicate that the change will increase the variance of the portfolio and vice versa for a negative derivative. Let $\hat{h}_{t}=\hat{z}_{t} \hat{\theta}$ be the estimated variance, where a hat $\left(^{\wedge}\right)$ above a variable denotes that the variable is evaluated at the estimated parameter. In computing the derivative of $\hat{h}_{t}$ one

\footnotetext{
${ }^{1}$ The zero-mean assumption is made only for the sake of simplicity and implies no loss of generality.

${ }^{2}$ The $(n+1)$-th weight is given by 1 minus the sum of the other weights. The corresponding $(n+1)$-th asset is the pivotal asset against which the sensitivity analysis is performed. By changing the pivotal asset, one obtains different sensitivity measures. Computing these sensitivity measures for each single asset of the portfolio, it is possible to compute a matrix of sensitivities analogous to the variance-covariance matrix.
} 
must recognise that not only the vector $\hat{z}_{t}$, but also the vector of estimated coefficients $\hat{\theta}$ depends on $a$. By the chain rule, the derivative of $\hat{h}_{t}$ with respect to $a$ is given by:

$$
\frac{\partial \hat{h}_{t}}{\partial a}=\frac{\partial \hat{z}_{t}^{\prime}}{\partial a} \underset{n x 1}{\hat{\theta}}+\frac{\partial \hat{\theta}^{\prime}}{\partial a} \hat{z}_{n \times m}
$$

To achieve a clearer picture of the local behaviour of the estimated variance with respect to the portfolio allocation, one could determine its degree of convexity by computing the second derivative:

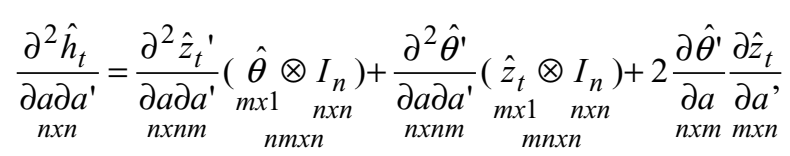

where $\otimes$ denotes the Kronecker product.

To evaluate (3) and (4), we need to compute $\frac{\partial \hat{\theta}^{\prime}}{\partial a}$ and $\frac{\partial^{2} \hat{\theta}^{\prime}}{\partial a \partial a^{\prime}}$, the other terms being easily obtained. We compute these derivatives by applying the Implicit Function Theorem to the first order conditions of the log-likelihood maximisation problem. Assuming that the standardised residuals are normally distributed, ${ }^{3}$ the first order conditions for model (1)-(2) are:

\footnotetext{
${ }^{3}$ If the variance equation is assumed to be correctly specified, Bollerslev and Wooldridge (1992) showed that the vector of unknown parameters $\theta$ can be consistently estimated by maximizing the normal loglikelihood.
} 


$$
T^{-1} \sum_{t=1}^{T} \frac{\partial l_{t}(\hat{\theta})}{\partial \theta}=0
$$

where $l_{t}(\theta)=-\frac{1}{2} \ln \left(h_{t}\right)-\frac{1}{2} y_{t}^{2} h_{t}^{-1}$ is the time $t$ component of the log-likelihood function ignoring constants. The following theorem derives the analytical expressions for $\frac{\partial \hat{\theta}}{\partial a}$ and $\frac{\partial^{2} \hat{\theta}^{\prime}}{\partial a \partial a^{\prime}}$.

$\underline{\text { Theorem } 1}-$ Let $\hat{I}_{\theta \theta} \equiv T^{-1} \sum_{t=1}^{T} \frac{\partial^{2} l_{t}(\hat{\theta})}{\partial \theta \partial \theta^{\prime}}$ and $\hat{I}_{\theta a} \equiv T^{-1} \sum_{t=1}^{T} \frac{\partial^{2} l_{t}(\hat{\theta})}{\partial \theta \partial a^{\prime}}$. If $\hat{I}_{\theta \theta}$ is nonsingular, then:

$$
\begin{aligned}
& \underset{m x n}{\frac{\partial \hat{\theta}}{\partial a}}=\underset{m x m}{-\left(\hat{I}_{\theta \theta}\right)^{-1}} \underset{m x n}{\left(\hat{I}_{\theta a}\right)} \\
& \frac{\partial^{2} \hat{\theta}}{\partial a \partial a_{k}}=-\left\{\left[\frac{\partial}{\partial a_{k}}\left(\hat{I}_{\theta \theta}\right)^{-1} \hat{I}_{\theta a}+\left(\hat{I}_{\theta \theta}\right)^{-1} \frac{\partial}{\partial a_{k}}\left(\hat{I}_{\theta a}\right)\right]\right\} \quad \text { for } k=1, \ldots, n
\end{aligned}
$$

Proof - Since the score is continuous and differentiable both in $a$ and $\theta$, if $\hat{I}_{\theta \theta}$ is non singular it is possible to apply the implicit function theorem to the first order conditions. The result follows.

Both $\hat{I}_{\theta \theta}$ and $\hat{I}_{\theta a}$ can be easily derived analytically, although the algebra might be messy. One may wonder how it is possible to compute the sensitivity of GARCH variances from the simple series of portfolio returns. In fact, formulae (6)-(7) and theorem 1 make use not only of portfolio returns, but also of the returns of the individual assets entering the information set. We illustrate this point with a simple 
example. Let $y_{t}=a y_{t, 1}+(1-a) y_{t, 2}$, where $a$ and $(1-a)$ are the weights associated to assets 1 and 2, respectively. Suppose that an $\operatorname{ARCH}(1)$ model is estimated, so that the parametric form of the estimated variance is $\hat{h}_{t}=\hat{\theta}_{t-1}^{2} \cdot{ }^{4}$ Then one can show that:

$$
\hat{I}_{\theta a} \equiv \hat{h}_{t}^{-2}\left[y_{t-1}^{2} y_{t}\left(y_{t, 1}-y_{t, 2}\right)+2 y_{t}^{2} y_{t-1}\left(y_{t-1,1}-y_{t-1,2}\right)\right]
$$

Hence, both formula (3) and theorem 1 exploit not only the information contained in $\left\{y_{t}\right\}_{t=1}^{T}$, but also that contained in the individual series $\left\{y_{t, 1}\right\}_{t=1}^{T}$ and $\left\{y_{t, 2}\right\}_{t=1}^{T}$.

\section{SENSITIVITY ANALYSIS CORRELATIONS}

In this section, we show how the GARCH sensitivity results can be used to obtain an estimate of the variance-covariance matrix. We first discuss some of the most popular existing models, and then introduce our sensitivity-based method that we call Sensitivity Analysis Correlation (SAC).

The multivariate GARCH model, initially proposed by Bollerslev, Engle and Wooldridge (1988), can, in principle, be estimated efficiently by maximum likelihood. However, the number of parameters to be estimated can be very large, requiring very large data sets and exceptional computing capacity. To make the estimation feasible it is necessary to impose often arbitrary restrictions. We refer to Bollerslev, Engle and Nelson (1994) for a detailed survey. For the purpose of this paper, we restrict our attention to three selected popular alternatives, against which the performance of our

\footnotetext{
${ }^{4}$ We left out the constant for the sake of simplicity.
} 
methodology will be evaluated: the Dynamic Conditional Correlation (DCC), the Orthogonal GARCH (OGARCH) and the Exponentially Weighted Moving Average (EWMA).

The Dynamic Conditional Correlation model has been recently proposed by Engle (2000) and Engle and Sheppard (2001). This can be seen as a generalisation of the Constant Conditional Correlation model, originally proposed by Bollerslev (1990). In the DCC model, conditional correlations are directly parameterised, rather than assumed constant. Engle (2000) shows that the estimation of the multivariate model can be drastically simplified, by using a two-step procedure. First the univariate GARCH models are estimated for each of the assets. Then the conditional correlation specification is fitted to the standardised residuals obtained in the first step. There are two drawbacks with this approach. First, no heterogeneous distributions across correlations is allowed (being the long run correlations set equal to sample correlations). Second, the same pair of parameters is estimated for all the correlations considered (implying that all correlations have the same degree of persistence).

Alexander and Chibumba (1995) propose the Orthogonal GARCH model, based on a principal component GARCH methodology. First, they construct unconditionally uncorrelated factors, which are linear combinations of the original returns. Then they fit univariate GARCH models to the principal components. Under the assumption that the conditional variance-covariance matrix of the principal component series is diagonal (i.e. conditional correlations are set to zero), it is possible to recover the original assets' variance-covariance matrix, through a fixed mapping matrix. A sufficiently long sample is needed not to encounter significant variability of this matrix, which might also be sensible to different calibration procedures. 
The last method we consider is the EWMA, popularised by RiskMetrics. With this method the variance-covariance matrix at time $t$ is simply computed as a convex combination of the variance-covariance matrix in the previous period, $t-1$, and the matrix of squared and cross-product lagged returns. The weight is usually set equal to 0.94 or 0.97 .

Let's see now how the sensitivity results of the previous section can be used to estimate full variance-covariance matrices. Consider, for the sake of simplicity, two assets ( $A$ and $B$ ), which enter the portfolio $P_{a}$ with weights $a$ and (1-a). In general, the variance of the portfolio can be expressed as a weighted sum of the variances of the individual assets and the covariances: $h_{t}^{(a)}=a^{2} h_{t, A}+(1-a)^{2} h_{t, B}+2 a(1-a) h_{t, A B}$, where $h_{t}^{(a)}, h_{t, A}, h_{t, B}$ denote portfolio and assets $A$ and $B$ variances, and $h_{t, A B}$ is the covariance between $A$ and $B$ (here all the terms denote population values). Differentiating with respect to $a$, we have:

$$
\frac{\partial h_{t}^{(a)}}{\partial a}=2 a h_{t, A}-2(1-a) h_{t, B}+2(1-2 a) h_{t, A B}
$$

Consider now the two degenerate portfolios $P_{1}$, composed entirely by asset $A$, and $P_{0}$, with only asset $B$, which correspond, respectively, to $a=1$ and $a=0$. Solving for $h_{t, A B}$ we get two equivalent expressions for the covariance:

$$
h_{t, A B}=h_{t, A}-\frac{1}{2} \frac{\partial h_{t}^{(1)}}{\partial a} \quad \text { and } \quad h_{t, A B}=h_{t, B}+\frac{1}{2} \frac{\partial h_{t}^{(0)}}{\partial a}
$$


Note that $h_{t}^{(1)}=h_{t, A}$ and $h_{t}^{(0)}=h_{t, B}$. An obvious estimator for the covariance is the one that replaces the right-hand side variables of the above expressions with their estimated values. $h_{t, A}$ and $h_{t, B}$ can be computed by fitting univariate GARCH models, while the derivatives are given in equation (3) and can be easily computed from the estimates of the individual assets univariate GARCH. Note that model (1)-(2) implies that the information set of the individual asset GARCH models is $\Omega_{t}=\left\{a, y_{t, A}, y_{t, B}\right\}$, so that, for example, square lagged returns of both assets could be used in the univariate estimation. $^{5}$

This procedure gives two different estimates of the covariance, $\hat{h}_{t, A B}^{(1)}$ and $\hat{h}_{t, A B}^{(0)}$, where the superscripts (1) and (0) refer to the two expressions in (10). To combine these two estimates in order to have an estimated correlation that is bounded by -1 and 1 , we appropriately rescale both the dependent and regressor variables and run the following modified logistic regression:

$$
\frac{y_{t, A} y_{t, B}}{\sqrt{\hat{h}_{t, A} \hat{h}_{t, B}}}=\Lambda\left(\beta_{1}, \beta_{2} \frac{\hat{h}_{t, A B}^{(1)}}{\sqrt{\hat{h}_{t, A} \hat{h}_{t, B}}}+\beta_{3} \frac{\hat{h}_{t, A B}^{(0)}}{\sqrt{\hat{h}_{t, A} \hat{h}_{t, B}}}\right)+\varepsilon_{t}
$$

The functional form $\Lambda\left(\beta_{1}, x\right) \equiv \frac{1-e^{-\beta_{1} x}}{1+e^{-\beta_{1} x}}$ is bounded between -1 and 1 over its entire domain. The estimated time-varying correlation coefficient $\hat{\rho}_{t}$ is given by the fitted value of the above regression. That is, if we let $\hat{x}_{t} \equiv \hat{\beta}_{2} \frac{\hat{h}_{t, A B}^{(1)}}{\sqrt{\hat{h}_{t, A} \hat{h}_{t, B}}}+\hat{\beta}_{3} \frac{\hat{h}_{t, A B}^{(0)}}{\sqrt{\hat{h}_{t, A} \hat{h}_{t, B}}}$ and

\footnotetext{
${ }^{5}$ Of course, a continuum of alternatives could be obtained from (9), by choosing $a \in(-\infty, \infty)$. This strategy, however, would require not only the estimation of the two degenerate portfolio variances, $h_{t, A}$ and $h_{t, B}$, but also of $h_{t}^{(a)}$. As the number of assets increases, this method would quickly become impractical.
} 
denote with $\hat{\beta}_{1}, \hat{\beta}_{2}$ and $\hat{\beta}_{3}$ the non-linear least squares estimators of equation (11), we have $\hat{\rho}_{t}=\frac{1-e^{-\hat{\beta}_{1} \hat{x}_{t}}}{1+e^{-\hat{\beta}_{1} \hat{x}_{t}}}$. Given the choice of the functional form, the estimated correlation coefficient will be guaranteed to lie in the interval $(-1,1)$.

This estimation procedure easily generalises to the case of an $(n+1)$-assets portfolio. Since in the $(n+1)$-assets case there are $(n+1) n / 2$ distinct covariance terms, one would have to run this same number of logistic regressions, in addition to $(n+1)$ univariate GARCH models. The main drawback when leaving the bivariate domain is that the mere fact that correlations are bounded between -1 and 1 does not guarantee any more a positive definite variance-covariance matrix. Whether this is a relevant problem is mainly an empirical question.

\section{EMPIRICAL APPLICATION}

In this section, we implement our methodology on a selected sample of stocks. We first estimate the sensitivity of GARCH variances on a two-stock portfolio, as described in section 2. Then we estimate full variance-covariance matrices for a ten-stock portfolio using the methodology outlined in section 3 , and compare its performance to that of a few popular alternatives (namely, Dynamic Conditional Correlation, orthogonal GARCH and Exponentially Weighted Moving Average). 


\subsection{Sensitivity of GARCH variance}

We estimated the first and second derivatives of GARCH variances as described in section 2, using a two-asset portfolio, composed by General Motors (GM) and IBM. Daily data are taken from Bloomberg and run from 2 January 1992 through 11 March 2002.

We estimate univariate $\operatorname{GARCH}(1,1)$ models for 31 portfolios constructed from these two assets, with the GM weight (a) ranging from -1 to 2 , with increments of 0.1 . For each estimated GARCH model, we computed the first and second derivatives of the estimated variance with respect to the weight $a$. In figure 1 we plot the estimated variances on 11 March 2002 for the 31 portfolios as a function of the weight, together with their first and second derivatives. Note that the variance corresponding to $a=0$ is the variance of IBM, while the variance corresponding to $a=1$ is the variance of GM. The portfolios with a weight greater than 1 or less than 0 are short on IBM or GM, respectively. The estimated variance plotted in figure 1 is a parabolic and convex function of the portfolio weights $a$, suggesting that diversification produces significant gains in terms of risk reduction. If the true variance-covariance matrix was available and one computes the portfolio variances as a weighted sum of the individual asset variances and their covariance, this function would be exactly a parabola. The fact that fitting univariate GARCH models to the time series of portfolios produces results very close to those one would expect in theory, indicates that these univariate GARCH models provide a reasonable approximation of the true (but unknown) model. This intuition is confirmed by the shape of the first and second derivatives. If the function were truly a parabola, than the first derivative would be a straight positively sloped line 
and the second derivative a flat line. The plots in figure 1 show that both the first and second derivatives are very close to their theoretical shape.

In figure 2, we report the time series of the first derivatives of the estimated variance, $\frac{\partial \hat{h}_{t}(a)}{\partial a}$, for the two degenerate portfolios, i.e. for IBM $(a=0)$ and GM $(a=1)$. The picture indicates by how much the variance would decrease or increase over time, if one diversifies away from the portfolios composed of only GM or IBM asset. Similar pictures can be drawn for any portfolio weight, thus giving the risk manager a precise indication about the consequences in terms of risk of changing the composition of the current portfolio.

A second interesting feature of figure 2 is that the first derivative is always positive for GM and almost always negative for IBM. This implies that the minimum variance portfolio during the period considered in this analysis was formed by a convex combination of these two assets. The fact that for a few days towards the end of the sample both first derivatives were positive signals that during those days the risk manager would have had to short GM to construct the minimum variance portfolio.

Figure 2 provides also an insight about the major sources of risk of a portfolio. Indeed, the greater (in absolute value) the first derivative, the greater will be the risk reduction following a portfolio reallocation. Figure 2 shows that the first derivative of the portfolio containing only the IBM asset is much higher on average (in absolute value) than the first derivative corresponding to the GM portfolio. ${ }^{6}$ This implies that during the 1990's an investor could achieve greater variance reduction by diversifying away from the portfolio with only IBM (the "new economy" stock), than from the GM

\footnotetext{
${ }^{6}$ The average first derivative for IBM is -1.495 and for GM is 1.22 . That is, the variance sensitivity of the portfolio containing only IBM was about $20 \%$ higher than that of the GM portfolio.
} 
portfolio (the "old economy" stock). In the case of a portfolio with more than two assets, one could compute the variance sensitivity corresponding to each asset and gain in this way an insight about the major sources of risk of the portfolio. In order to reduce the risk, the risk manager should sell the assets with highest first derivative and buy those with the lowest one.

In figure 3 we report the time series of the second derivatives, for the two degenerate portfolios, GM and IBM. In theory, for a correctly specified model, the second derivative should not depend on the portfolio composition, as it should be a flat line. As expected, the two graphs in figure 3 are very similar, obtaining once again evidence that portfolio univariate GARCH models provide a good approximation of the true variance.

The second derivative, being the slope of the first derivative, tells the risk manager by how much the variance sensitivity will change after a change in the portfolio allocation. The greater the magnitude of the second derivative, the greater will be the change in the variance sensitivity, implying that a smaller portfolio reallocation will be necessary to achieve a given size of variance reduction. Figure 3 shows that in the last couple of years portfolio reallocations had much greater impact on the variance than during the 90's. The average of the second derivative was 2.36 between 1992 and 1999, and rose to 3.38 from 1999 to 2002 . In other words, these results show that the concavity of the portfolio variance (as a function of the weight $a$ ) has increased dramatically over the past few years, for GM and IBM. This has obvious important consequences for managing the risk of a portfolio composed by these two assets. 


\subsection{Variance-Covariance Estimation}

In this subsection we implement the methodology described in section 3 to estimate full variance-covariance matrices. We tested our methodology on a sample of 10 stocks, with the same time span as before, i.e. from 2 January 1992 through 11 March 2002. The stocks are part of the Dow Jones index and were classified in two groups: 1) old economy and 2) new economy. In the first group we put Boeing, Coca Cola, General Electrics, General Motors and Mc Donald. In the second group we have Hewlett Packard, Intel, IBM, Microsoft and 3M.

Table 1 reports some summary statistics. Both the mean and the median of the returns (expressed in percentage points) are practically zero. The standard deviations for the two groups of stocks signals that the new economy group has been on average more volatile than the old economy group. The only exception is $3 \mathrm{M}$, which has the lowest standard deviation of all the 10 stocks. The Jarque-Bera test overwhelmingly rejects the normality assumption for all the stock returns in the sample. This is also confirmed by the very high kurtosis.

In table 2 we report the sample correlations of the returns. The average correlation for the old economy stocks is 0.25 and for the new economy stocks is 0.28 . The average correlation across the two groups of stocks is 0.21 . The highest correlation is the one between Intel and Microsoft (0.54), while the lowest is that between Intel and Coca Cola (0.10).

We implemented four different multivariate methodologies to estimate the variance-covariance matrix: 1) Dynamic Conditional Correlation (DCC), 2) Orthogonal GARCH (OGARCH), 3) Exponentially Weighted Moving Average (EWMA), and 4) 
Sensitivity Analysis Correlation (SAC). The decay coefficient for the EWMA was set equal to 0.94 .

In figure 4 we plot the estimated correlation between GM and IBM, according to the four different models. The general pattern is very similar, with correlations oscillating around 0.2 , increasing between 1998 and 2000 and towards the end of the sample. However, the DCC correlation appears to be much less volatile than the others, while EWMA correlation is the most volatile. In figure 5 we report the variance of the portfolio composed by $60 \%$ of group 1 stocks and $40 \%$ of group 2 stocks (stocks within the same group are given the same weight). Here again the estimated variances seem to follow very similar patterns, with spikes around 1998 and towards the end of the sample. In this graph, however, DCC and SAC variances are very similar, providing more conservative estimates of the variance than OGARCH and EWMA.

Following Granger and Newbold (1986), Andersen and Bollerslev (1998) and Andersen et al. (2002), and as originally suggested by Mincer and Zarnowitz (1969), we evaluate the performance of the different models by projecting the absolute values of portfolio returns on a constant and the alternative volatility estimates:

$$
\left|y_{t}\right|=b_{0}+b_{1} \sqrt{\hat{h}_{t}^{A}}+b_{2} \sqrt{\hat{h}_{t}^{B}}+\varepsilon_{t}
$$

where $\hat{h}_{t}^{A}$ and $\hat{h}_{t}^{B}$ represent the estimated variance of two competing models. Estimate A is efficient if $b_{0}=b_{2}=0$ and $b_{1}=1$. Alternatively, one could look at the $R^{2}$ of the regression. The higher the variation explained by the model estimate, the better the model. As originally pointed out by Andersen and Bollerslev (1998), $\left|y_{t}\right|$ is a very noisy proxy for the true volatility. Thus one should not expect very high $R^{2}$ from these 
regressions. A more precise measure of volatility is given by the realised volatility, as suggested by Andersen et al. (2002). However, the implementation of this measure requires the availability of high frequency data and is beyond the scope of this paper.

We report the results of the regressions (12) in table 3. We constructed six different portfolios by giving different weights to the two groups of stocks. These weights ranged from 0 (corresponding to a portfolio with only new economy stocks) to 1 (old economy portfolio), with increments of 0.2 . All the stocks within the same group were given the same weight. For each of these six portfolios we ran 7 different regressions. First we projected the absolute values of portfolio returns on a constant and only one estimated volatility. Then we projected them on a constant, the SAC estimated volatility and each of the alternative estimates. In the table, below each coefficient we report in italic the $t$-statistics, computed using White heteroscedasticity robust standard errors.

The results reported in the table show that DCC and SAC models clearly dominate the other two. The DCC model produced the highest $R^{2}$ for the first two portfolios, while the $R^{2}$ of the SAC model was the highest in the remaining four portfolios. These results are confirmed by looking at the coefficients of the estimated regression. For OGARCH and EWMA we always strongly reject the null hypothesis $H_{0}$ : $b_{1}=1$. The coefficients associated to DCC and SAC are much closer to 1 and for half of the portfolios we cannot reject $H_{0}$ at the $1 \%$ confidence level. Finally, the pair comparisons also indicate the clear superiority of SAC relative to OGARCH and EWMA, while the comparison between SAC and DCC appears to confirm those from the $R^{2}$, with the DCC dominating for the first two portfolios, and SAC outperforming DCC in the rest of the cases. 


\section{CONCLUSIONS}

Fitting variance models directly to the time series of portfolio returns has many advantages, such as the possibility of estimating parsimonious models and computational tractability. The problem of this strategy is that the multivariate dimension of the portfolio allocation is lost. This paper suggested a strategy to overcome this problem, working within a GARCH framework. We assessed the potential impact of a trade on the estimated variance by computing the sensitivity of the estimated variance with respect to the weight of the asset involved in the trade. This sensitivity measure is simply the derivative of the estimated variance with respect to the portfolio weights. As a by-product of this analysis, we proposed a new and simple method to estimate full variance-covariance matrices, which exploits the analytical relationship among variances, covariances and sensitivity measures.

We illustrated the functioning and the performance of our methodology with two empirical applications. In the first one, we estimated the variance sensitivity for a portfolio of two assets. We documented how this sensitivity has been changing over time and stressed its implications for risk management. We also computed the second derivative of the estimated variance with respect to the portfolio weights. We argued that this measure gives an indication of the diversification opportunities at any given point in time: the higher this second derivative, the greater the gains (in terms of variance reduction) from a proper diversification strategy.

In the second application, we implemented the suggested methodology (which we call the Sensitivity Analysis Correlation (SAC) model) to estimate full variancecovariance matrices. We tested the model with a sample of 10 stocks, taken from the Dow Jones index. We evaluated the performance of our methodology against that of 
popular alternatives, including the Dynamic Conditional Correlation (DCC), the Orthogonal GARCH and the Exponentially Weighted Moving Average models. Our tests suggest that the performance of the proposed method is comparable with the DCC model, and superior to that of the other two models.

\section{REFERENCES}

Andersen, T.G. and T. Bollerslev (1997), "Answering the Skeptics: Yes, Standard Volatility Models do Provide Accurate Forecasts", Journal of Empirical Finance, 4: 115-158.

Andersen, T., Bollerslev, T., Diebold, F.X. and Labys, P. (2002), "Modeling and Forecasting Realized Volatility," Manuscript, Departments of Economics, Northwestern University, Duke University and University of Pennsylvania.

Alexander, C. and A.M. Chibumba (1995), "Multivariate Orthogonal Factor Garch", University of Sussex Discussion Papers in Mathematics.

Bollerslev, T. (1990), "Modelling the Coherence in Short-Run Nominal Exchange Rates: A Multivariate Generalized ARCH Approach", Review of Economics and Statistics, 72: 498-505.

Bollerslev, T., R.F. Engle and D. Nelson (1994), ARCH Models, Ch. 49 in R.F. Engle and D.L. McFadden eds., Handbook of Econometrics, iv Elsevier.

Bollerslev, T., R.F. Engle and J.M. Wooldridge (1988), “A Capital-Asset Pricing Model with Time Varying Covariances”, Journal of Political Economy, 96: 116-131.

Bollerslev, T. and J. Wooldridge (1992), "Quasi-Maximum Likelihood Estimation and Inference in Dynamic Models with Time Varying Covariances, Econometric Reviews 11: $143-172$.

Engle, R.F. (1982), “Autoregressive Conditional Heteroscedasticity with Estimates of the Variance of United Kingdom Inflation”, Econometrica, 50: 987-1007.

Engle, R.F. (2000), "Dynamic Conditional Correlation - A Simple Class of Multivariate GARCH Models", UCSD Discussion Paper.

Engle, R.F. and K. F. Kroner (1995), "Multivariate Simultaneous Generalized ARCH", Econometric Theory, 11: 122-150. 
Engle, R.F. and K. Sheppard (2001), "Theoretical and Empirical Properties of Dynamic Conditional Correlation Multivariate GARCH”, UCSD Discussion Paper 2001-15.

Gourieroux, C., J.P. Laurent and O. Scaillet (2000), "Sensitivity Analysis of Values at Risk", Journal of Empirical Finance, 7: 225-245.

Garman M. (1996), “Improving on VaR”, Risk, 9: 61-63.

Granger, C. and P. Newbold (1986), Forecasting Economic Time Series, Academic Press, San Diego, Second Edition.

McNeil, A.J. and R. Frey (2000), "Estimation of tail related risk measures for heteroskedastic financial time series: an extreme value approach", Journal of Empirical Finance, 7: 271-300.

Mincer, J. and V. Zarnowitz (1969), "The evaluation of economic forecasts", in Economic Forecasts and Expectations (J. Mincer, ed.), New York: National Bureau of Economic Research.

West, K., H.J. Edison and D. Cho (1992), "A Utility Based Comparison of Some Models of Exchange Rate Volatility", Journal of International Economics, 35: 23-45. 


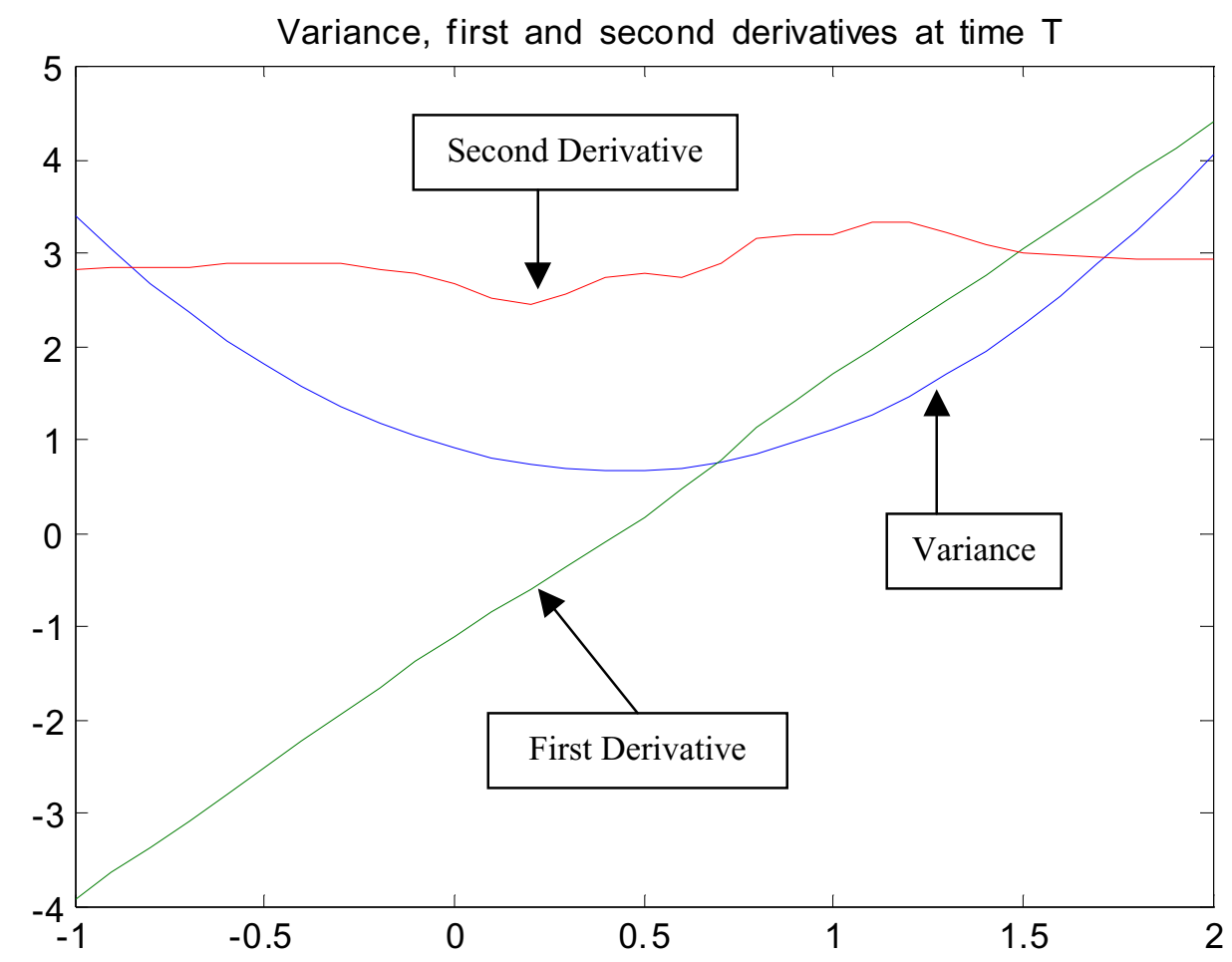

Figure 1 - Plot of estimated variance, first and second derivative on 11 March 2002, for 31 portfolios constructed from GM and IBM. On the horizontal axis there is the portfolio weight for GM, which ranges from -1 to 2 , with increments of 0.1 . The variance is computed by re-estimating a $\operatorname{GARCH}(1,1)$ model for each of the 31 portfolios. The first and second derivatives are computed analytically, as described in section 2 .

First derivative of $\mathrm{GM}$ and IBM

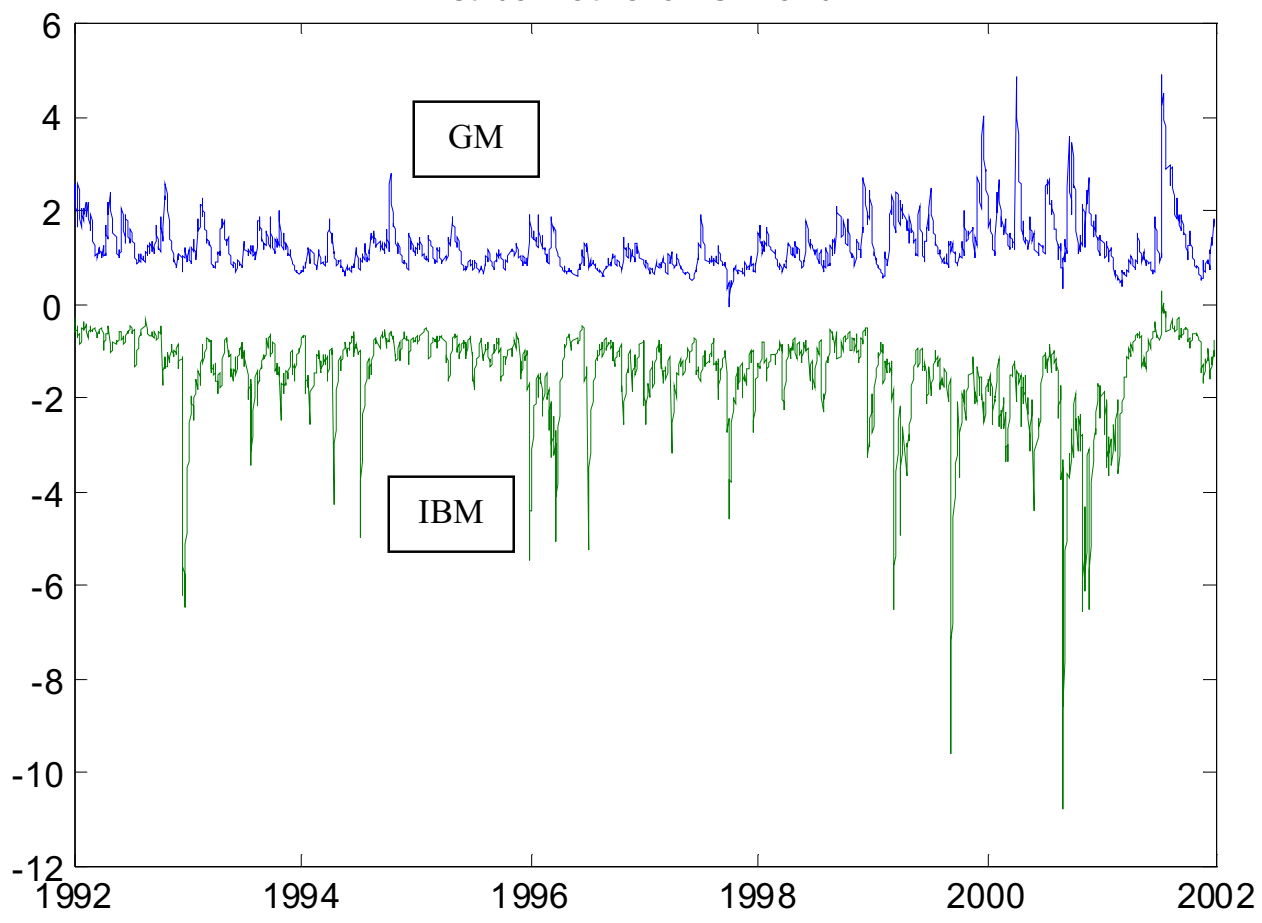

Figure 2 - Plot of variance sensitivities for the two degenerate portfolios GM and IBM. The variance sensitivity indicates by how much the variance would increase or decrease over time, if one increases the weight of GM in the portfolio. In the case the portfolio is composed of only GM, buying an extra share of GM and going short of IBM would increase the overall portfolio variance (upper line). Vice versa, diversifying away from a portfolio composed of only IBM stocks would decrease the variance (bottom line). 

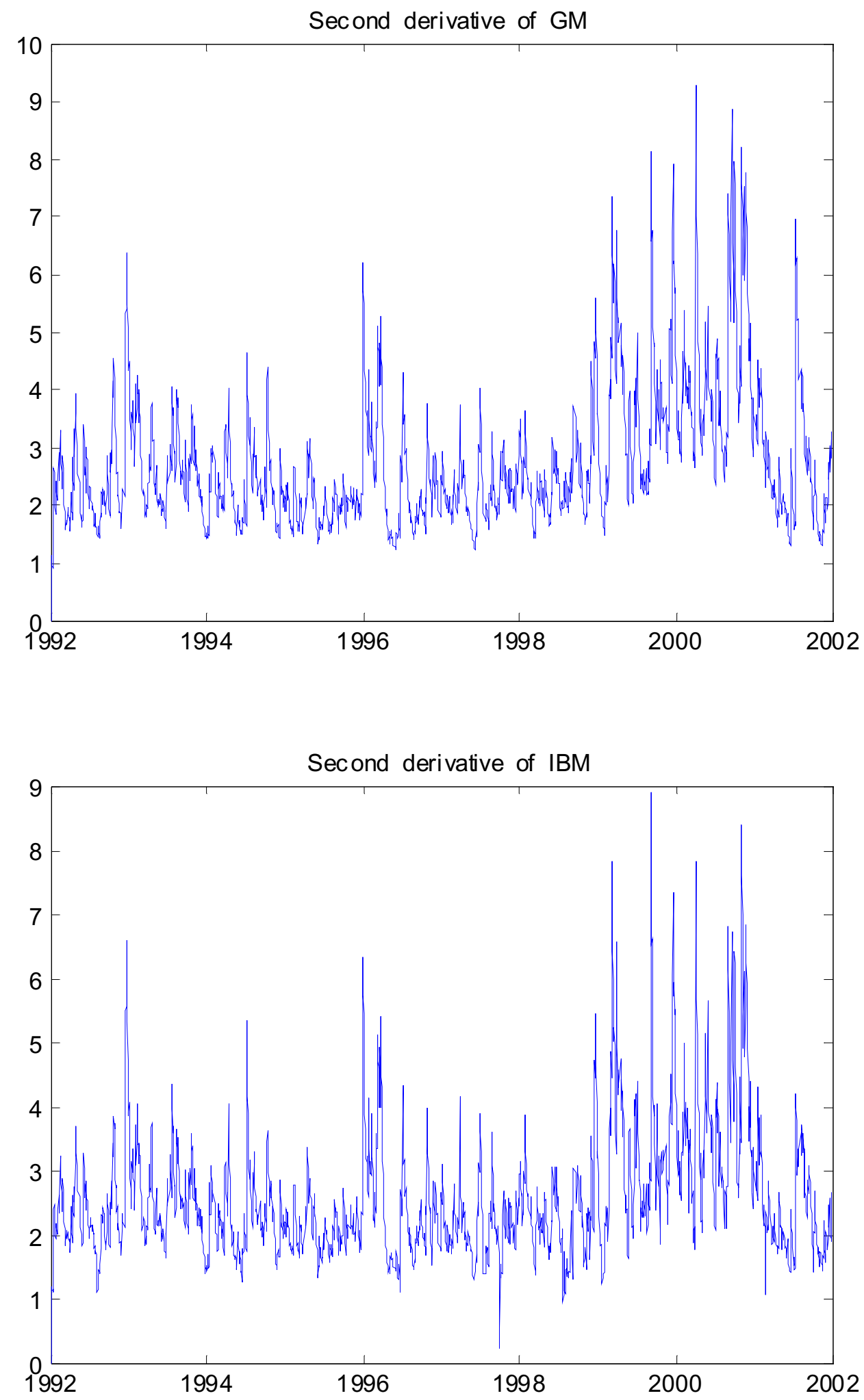

Figure 3 - Plot of the estimated second derivatives, computed from the degenerate GM portfolio (upper graph) and the degenerate IBM portfolio (lower graph). Under correct model specification, the second derivative should not depend on the portfolio weight. Hence the two graphs should be exactly the same. The striking similarity among these two graphs confirms the results obtained in figure 1, i.e. that $\operatorname{GARCH}(1,1)$ model provides a reasonable approximation of the variance process. 

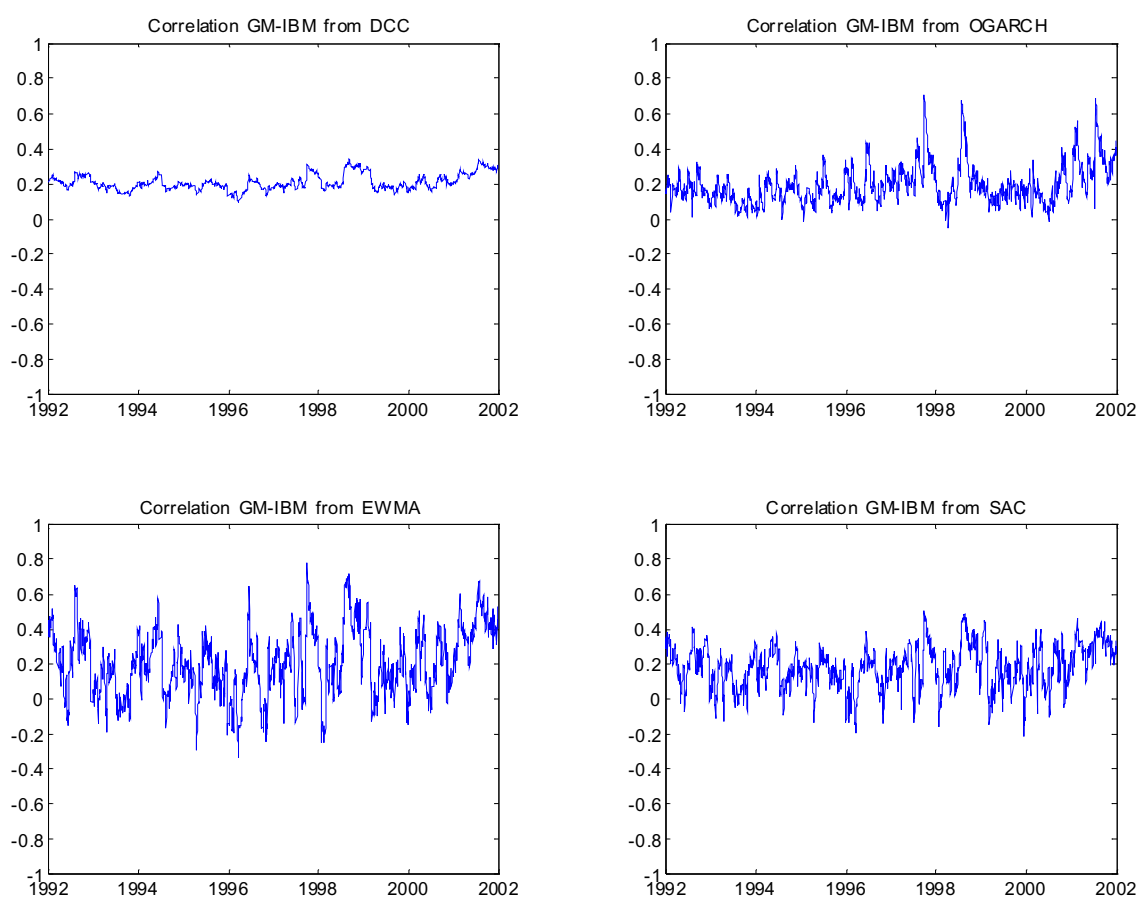

Figure 4 - Plot of estimated correlations between GM and IBM, according to four different models applied to the full sample of 10 stocks. The plotted correlations have a very similar pattern, although DCC correlation seems to be less volatile and EWMA correlation more volatile than the others.
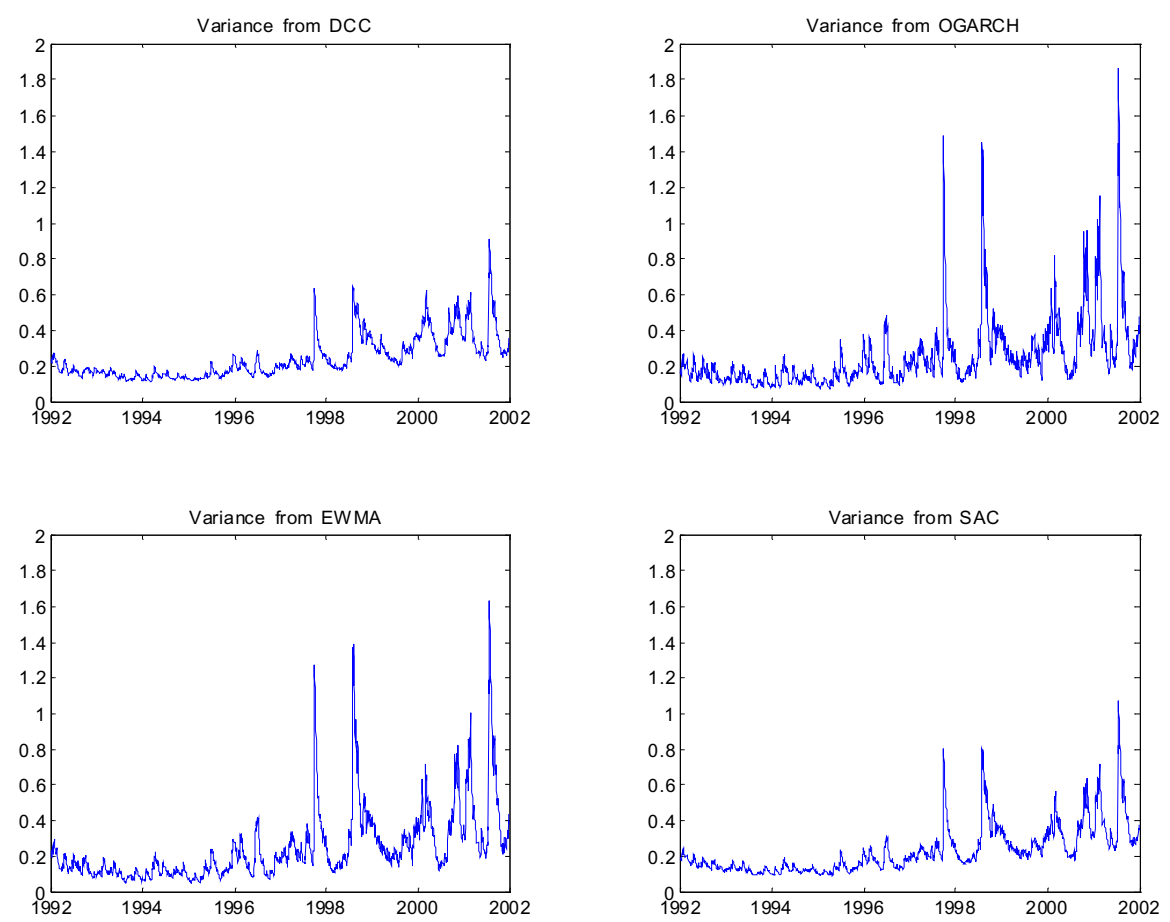

Figure 5 - Plot of estimated variances for the portfolio composed by $60 \%$ of old economy stocks and $40 \%$ of new economy stocks. The overall patterns are very similar, although DCC and SAC estimated variances are much lower than the others. 
Table 1 - Summary statistics for the 10 stocks used in the analysis. The stocks were divided into two groups, an old economy group and a new economy one. The standard deviation of the new economy stocks is significantly higher than that for the old economy group. The high kurtosis and Jarque-Bera statistic indicate that the normality assumption is rejected for all the stocks in the sample.

\begin{tabular}{|c|ccccc|ccccc|}
\hline & BA & GE & GM & KO & MCD & INTC & HWP & IBM & MMM & MSFT \\
\hline Mean & 0.01 & 0.03 & 0.02 & 0.01 & 0.02 & 0.05 & 0.02 & 0.03 & 0.02 & 0.04 \\
Median & 0.00 & 0.00 & 0.00 & 0.00 & 0.00 & 0.04 & 0.00 & 0.00 & 0.00 & 0.00 \\
Maximum & 4.78 & 5.10 & 3.22 & 4.07 & 4.48 & 7.96 & 6.93 & 5.37 & 4.56 & 7.76 \\
Minimum & -8.42 & -4.90 & -6.31 & -4.81 & -4.67 & -10.81 & -8.99 & -7.34 & -4.38 & -7.36 \\
Std. Dev. & 0.88 & 0.73 & 0.88 & 0.74 & 0.74 & 1.24 & 1.20 & 0.94 & 0.69 & 1.02 \\
Skewness & -0.68 & -0.04 & -0.08 & 0.00 & 0.07 & -0.29 & -0.19 & -0.01 & 0.10 & -0.10 \\
Kurtosis & 12.38 & 6.91 & 4.97 & 6.23 & 6.20 & 7.69 & 8.29 & 8.68 & 6.50 & 7.28 \\
& & & & & & & & & & \\
Jarque-Bera & 9621 & 1639 & 416 & 1114 & 1094 & 2392 & 3008 & 3451 & 1312 & 1965 \\
Probability & 0.00 & 0.00 & 0.00 & 0.00 & 0.00 & 0.00 & 0.00 & 0.00 & 0.00 & 0.00 \\
\hline
\end{tabular}

Table 2 - Sample correlations for the 10 stocks used in the analysis. The average correlation for the old economy stocks is 0.25 , for the new economy stocks is 0.28 and across the two groups is 0.21 . The highest correlation in the sample is the one between Intel and Microsoft (0.54). The lowest correlation is that between Intel and Coca Cola (0.10).

\begin{tabular}{ccccccccccc}
\hline & BA & GE & GM & KO & MCD & INTC & HWP & IBM & MMM & MSFT \\
\hline BA & 1.00 & & & & & & & & & \\
GE & 0.32 & 1.00 & & & & & & & \\
GM & 0.20 & 0.33 & 1.00 & & & & & & \\
KO & 0.19 & 0.33 & 0.14 & 1.00 & & & & & \\
MCD & 0.17 & 0.29 & 0.17 & 0.29 & 1.00 & & & & \\
INTC & 0.19 & 0.31 & 0.26 & 0.10 & 0.14 & 1.00 & & & \\
HWP & 0.17 & 0.30 & 0.22 & 0.12 & 0.16 & 0.44 & 1.00 & & \\
IBM & 0.17 & 0.31 & 0.21 & 0.11 & 0.17 & 0.39 & 0.40 & 1.00 & & \\
MMM & 0.26 & 0.34 & 0.27 & 0.24 & 0.17 & 0.18 & 0.16 & 0.17 & 1.00 & \\
MSFT & 0.19 & 0.35 & 0.25 & 0.16 & 0.15 & 0.54 & 0.38 & 0.34 & 0.14 & 1.00 \\
\hline
\end{tabular}


Table 3 - Output of the regression $\left|y_{t}\right|=b_{0}+b_{1} \sqrt{\hat{h}_{t}^{A}}+b_{2} \sqrt{\hat{h}_{t}^{B}}+\varepsilon_{t}$ for six different portfolios. The portfolios are constructed using weights for the group of old economy stocks that range from 0 to 1 , with increments of 0.2 . For each portfolio we highlighted the best performing model (among the four alternatives considered) according to the $R^{2}$ criterion. Below each coefficient, we report in italic the tstatistics, computed using White hetereoscedasticity consistent standard errors. When the null hypothesis of $b_{0}=0, b_{1}=b_{2}=1$ is rejected at the $1 \%$ confidence level, we format the corresponding coefficients in bold.

\begin{tabular}{ccccc}
\hline Weight $=0$ & $\mathrm{~b} 0$ & $\mathrm{~b} 1$ & $\mathrm{~b} 2$ & $\mathrm{R} 2$ \\
\hline DCC & -0.1143 & 0.9410 & & $\mathbf{0 . 0 8 7 9}$ \\
& -2.1079 & 0.6994 & & 0.0813 \\
OGARCH & 0.0790 & $\mathbf{0 . 6 6 1 1}$ & & 0.0828 \\
& 1.9845 & $\mathbf{5 . 3 5 7 8}$ & & \\
EWMA & $\mathbf{0 . 1 2 5 9}$ & $\mathbf{0 . 6 0 3 0}$ & & 0.0874 \\
& 3.7106 & $\mathbf{7 . 1 6 8 5}$ & & \\
SAC & -0.0381 & 0.8367 & & 0.0887 \\
& -0.8043 & 2.1819 & & \\
SAC+DCC & -0.0880 & 0.3697 & 0.5359 & 0.0900 \\
SAC+OGARCH & -1.4879 & 2.0161 & 1.3132 & \\
& -0.0256 & $\mathbf{0 . 5 6 4 8}$ & $\mathbf{0 . 2 5 2 3}$ & 0.0876 \\
SAC+EWMA & -0.5382 & $\mathbf{2 . 8 4 5 5}$ & $\mathbf{5 . 8 7 0 7}$ & \\
& -0.0672 & 1.0050 & $\mathbf{- 0 . 1 2 7 1}$ & $\mathbf{5 . 1 8 0 3}$ \\
\hline
\end{tabular}

\begin{tabular}{ccccc}
\hline Weight $=0.2$ & $\mathrm{~b} 0$ & $\mathrm{~b} 1$ & $\mathrm{~b} 2$ & $\mathrm{R} 2$ \\
\hline DCC & -0.1050 & 0.9460 & & $\mathbf{0 . 0 8 6 9}$ \\
& -2.2700 & 0.6510 & & 0.0815 \\
OGARCH & 0.0798 & $\mathbf{0 . 6 4 0 0}$ & & \\
& 2.3000 & $\mathbf{5 . 6 9 0 0}$ & & 0.0815 \\
EWMA & $\mathbf{0 . 1 1 3 0}$ & $\mathbf{0 . 5 9 4 0}$ & & 0.0865 \\
& $\mathbf{3 . 9 0 0 0}$ & $\mathbf{7 . 4 6 0 0}$ & & \\
SAC & -0.0296 & 0.8330 & & 0.0878 \\
& -0.7340 & 2.2600 & & \\
SAC+DCC & -0.0780 & 0.3770 & 0.5290 & 0.0883 \\
SAC+OGARCH & -1.5500 & 2.1400 & 1.4400 & \\
& -0.0106 & 0.5670 & $\mathbf{0 . 2 3 1 0}$ & 0.0867 \\
SAC+EWMA & -0.2610 & 2.4400 & $\mathbf{5 . 1 0 0 0}$ & \\
& -0.0659 & 1.0700 & $\mathbf{- 0 . 1 8 0 0}$ & $\mathbf{5 . 2 3 0 0}$ \\
\hline
\end{tabular}

\begin{tabular}{ccccc}
\hline Weight $=0.4$ & $\mathrm{~b} 0$ & $\mathrm{~b} 1$ & $\mathrm{~b} 2$ & $\mathrm{R} 2$ \\
\hline DCC & -0.0899 & 0.9350 & & 0.0853 \\
& -2.2700 & 0.8070 & & \\
OGARCH & 0.0730 & $\mathbf{0 . 6 3 2 0}$ & & 0.0836 \\
& 2.4000 & $\mathbf{5 . 8 6 0 0}$ & & \\
EWMA & $\mathbf{0 . 1 0 4 0}$ & $\mathbf{0 . 5 8 3 0}$ & & 0.0811 \\
& $\mathbf{4 . 1 4 0 0}$ & $\mathbf{7 . 7 8 0 0}$ & & \\
SAC & -0.0211 & 0.8270 & & $\mathbf{0 . 0 8 6 0}$ \\
SAC+DCC & -0.6110 & 2.3900 & & 0.0868 \\
SAC+OGARCH & -0.0564 & 0.4810 & 0.4040 & 0.0874 \\
& -1.3400 & 1.8700 & 1.9500 & \\
SAC+EWMA & 0.0041 & 0.5250 & $\mathbf{0 . 2 4 9 0}$ & 0.0864 \\
& -0.0624 & 2.2200 & $\mathbf{4 . 0 6 0 0}$ & \\
\hline
\end{tabular}


Table 3 continued

\begin{tabular}{ccccc}
\hline Weight $=0.6$ & $\mathrm{~b} 0$ & $\mathrm{~b} 1$ & $\mathrm{~b} 2$ & $\mathrm{R} 2$ \\
\hline DCC & -0.0632 & 0.8910 & & 0.0823 \\
& -1.8200 & 1.4100 & & 0.0833 \\
OGARCH & 0.0630 & $\mathbf{0 . 6 3 4 0}$ & & 0.0799 \\
& 2.2400 & $\mathbf{5 . 7 5 0 0}$ & & \\
EWMA & $\mathbf{0 . 1 0 1 0}$ & $\mathbf{0 . 5 6 7 0}$ & & $\mathbf{0 . 0 8 4 2}$ \\
& $\mathbf{4 . 3 8 0 0}$ & $\mathbf{8 . 0 3 0 0}$ & & 0.0846 \\
SAC & -0.0101 & $\mathbf{0 . 8 0 9 0}$ & & 0.0855 \\
SAC+DCC & -0.3220 & $\mathbf{2 . 6 3 0 0}$ & & \\
& -0.0308 & 0.5720 & $\mathbf{0 . 2 7 2 0}$ & $\mathbf{2 . 5 2 0 0}$ \\
SAC+OGARCH & -0.8830 & 1.5600 & $\mathbf{0 . 2 8 4 0}$ & \\
& 0.0148 & 0.4630 & $\mathbf{3 . 5 9 0 0}$ & \\
SAC+EWMA & 0.5190 & 2.4300 & $\mathbf{0 . 2 7 5 0}$ & $\mathbf{4 . 5 8 0 0}$ \\
& -0.0565 & 1.1900 & & \\
\hline
\end{tabular}

\begin{tabular}{ccccc}
\hline Weight $=0.8$ & $\mathrm{~b} 0$ & $\mathrm{~b} 1$ & $\mathrm{~b} 2$ & $\mathrm{R} 2$ \\
\hline DCC & -0.0327 & 0.8270 & & 0.0792 \\
& -1.0200 & 2.3400 & & \\
OGARCH & 0.0496 & $\mathbf{0 . 6 5 3 0}$ & & 0.0796 \\
& 1.7600 & $\mathbf{5 . 2 6 0 0}$ & & \\
EWMA & $\mathbf{0 . 1 0 0 0}$ & $\mathbf{0 . 5 5 8 0}$ & & 0.0790 \\
& $\mathbf{4 . 4 5 0 0}$ & $\mathbf{8 . 0 7 0 0}$ & & \\
SAC & -0.0032 & $\mathbf{0 . 7 9 2 0}$ & & $\mathbf{0 . 0 8 2 3}$ \\
SAC+DCC & -0.1050 & $\mathbf{2 . 8 1 0 0}$ & & 0.0824 \\
& -0.0104 & 0.6730 & $\mathbf{0 . 1 3 0 0}$ & \\
SAC+OGARCH & -0.3390 & 1.1200 & $\mathbf{3 . 0 2 0 0}$ & 0.0836 \\
& 0.0068 & $\mathbf{0 . 5 1 5 0}$ & $\mathbf{0 . 2 4 7 0}$ & \\
SAC+EWMA & 0.2320 & $\mathbf{2 . 8 1 0 0}$ & $\mathbf{4 . 7 2 0 0}$ & \\
& -0.0412 & 1.1100 & $\mathbf{- 0 . 2 3 0 0}$ & 0.0826 \\
\hline
\end{tabular}

\begin{tabular}{ccccc}
\hline Weight $=1$ & $\mathrm{~b} 0$ & $\mathrm{~b} 1$ & $\mathrm{~b} 2$ & $\mathrm{R} 2$ \\
\hline DCC & -0.0007 & $\mathbf{0 . 7 5 7 0}$ & & 0.0728 \\
& -0.0227 & $\mathbf{3 . 4 0 0 0}$ & & \\
OGARCH & 0.0432 & $\mathbf{0 . 6 6 8 0}$ & & 0.0708 \\
& 1.4500 & 4.9300 & & \\
EWMA & $\mathbf{0 . 1 0 9 0}$ & $\mathbf{0 . 5 4 5 0}$ & & 0.0729 \\
& 4.5900 & $\mathbf{8 . 1 8 0 0}$ & & \\
SAC & 0.0081 & $\mathbf{0 . 7 6 2 0}$ & & $\mathbf{0 . 0 7 4 4}$ \\
& 0.2470 & $\mathbf{3 . 1 7 0 0}$ & & \\
SAC+DCC & 0.0022 & 0.5540 & $\mathbf{0 . 2 1 4 0}$ & 0.0746 \\
SAC+OGARCH & 0.0689 & 1.3900 & $\mathbf{2 . 6 3 0 0}$ & \\
& 0.0056 & $\mathbf{0 . 4 9 2 0}$ & $\mathbf{0 . 2 6 7 0}$ & 0.0764 \\
SAC+EWMA & 0.1710 & 3.5300 & $\mathbf{5 . 7 5 0 0}$ & \\
& 0.0107 & 0.7410 & $\mathbf{0 . 0 1 5 0}$ & 0.0744 \\
\hline
\end{tabular}




\section{European Central Bank working paper series}

For a complete list of Working Papers published by the ECB, please visit the ECB's website (http://www.ecb.int).

II 3 "Financial frictions and the monetary transmission mechanism: theory, evidence and policy implications” by C. Bean, J. Larsen and K. Nikolov, January 2002.

II4 "Monetary transmission in the euro area: where do we stand?" by I. Angeloni, A. Kashyap, B. Mojon, D. Terlizzese, January 2002.

I 15 "Monetary policy rules, macroeconomic stability and inflation: a view from the trenches" by A. Orphanides, December 2001 .

II6 "Rent indices for housing in West Germany 1985 to 1998" by J. Hoffmann and C. Kurz., January 2002.

II7 "Hedonic house prices without characteristics: the case of new multiunit housing" by O. Bover and P. Velilla, January 2002.

I 18 "Durable goods, price indexes and quality change: an application to automobile prices in Italy, 1988-1998” by G. M. Tomat, January 2002.

I 19 "Monetary policy and the stock market in the euro area" by N. Cassola and C. Morana, January 2002.

120 "Learning stability in economics with heterogenous agents" by S. Honkapohja and K. Mitra, January 2002.

12I “Natural rate doubts" by A. Beyer and R. E. A. Farmer, February 2002.

122 "New technologies and productivity growth in the euro area" by F. Vijselaar and R. Albers, February 2002.

I 23 "Analysing and combining multiple credit assessments of financial institutions" by E. Tabakis and A. Vinci, February 2002.

124 "Monetary policy, expectations and commitment" by G. W. Evans and S. Honkapohja, February 2002.

I25 "Duration, volume and volatility impact of trades" by S. Manganelli, February 2002.

126 "Optimal contracts in a dynamic costly state verification model" by C. Monnet and E. Quintin, February 2002.

127 "Performance of monetary policy with internal central bank forecasting" by S. Honkapohja and K. Mitra, February 2002.

I 28 "Openness, imperfect exchange rate pass-through and monetary policy" by F. Smets and R. Wouters, February 2002. 
129 "Non-standard central bank loss functions, skewed risks, and certainty equivalence" by A. al-Nowaihi and L. Stracca, March 2002.

130 "Harmonized indexes of consumer prices: their conceptual foundations" by E. Diewert, March 2002.

I3I "Measurement bias in the HICP: what do we know, and what do we need to know?" by M. A. Wynne and D. Rodríguez-Palenzuela, March 2002.

132 "Inflation dynamics and dual inflation in accession countries: a "new Keynesian" perspective” by O. Arratibel, D. Rodríguez-Palenzuela and C. Thimann, March 2002.

I33 "Can confidence indicators be useful to predict short term real GDP growth?" by A. Mourougane and M. Roma, March 2002.

134 "The cost of private transportation in the Netherlands, 1992-1999" by B. Bode and J. Van Dalen, March 2002.

135 "The optimal mix of taxes on money, consumption and income" by F. De Fiore and P. Teles, April 2002.

136 "Retail bank interest rate pass-through: the new evidence at the euro area level" by G. de Bondt, April 2002.

137 "Equilibrium bidding in the eurosystem's open market operations" by U. Bindseil, April 2002.

138 "New" views on the optimum currency area theory: what is EMU telling us?" by F. P. Mongelli, April 2002.

139 “On currency crises and contagion” by M. Fratzscher, April 2002.

140 "Price setting and the steady-state effects of inflation" by M. Casares, May 2002.

14I “Asset prices and fiscal balances” by F. Eschenbach and L. Schuknecht, May 2002.

142 "Modelling the daily banknotes in circulation in the context of the liquidity management of the European Central Bank", by A. Cabrero, G. Camba-Mendez, A. Hirsch and F. Nieto, May 2002.

143 “A non-parametric method for valuing new goods”, by I. Crawford, May 2002.

144 "A failure in the measurement of inflation: results from a hedonic and matched experiment using scanner data", by M. Silver and S. Heravi, May 2002.

145 "Towards a new early warning system of financial crises”, by M. Fratzscher and M. Bussiere, May 2002.

I46 “Competition and stability - what's special about banking?", by E. Carletti and P. Hartmann, May 2002. 
I 47 "Time-to-build approach in a sticky price, stricky wage optimizing monetary model, by M. Casares, May 2002.

I 48 "The functional form of yield curves" by V. Brousseau, May 2002.

149 "The Spanish block of the ESCB-multi-country model" by A. Estrada and A. Willman, May 2002.

150 "Equity and bond market signals as leading indicators of bank fragility" by R. Gropp, J. Vesala and G. Vulpes, June 2002.

I5I “G-7 inflation forecasts” by F. Canova, June 2002.

152 "Short-term monitoring of fiscal policy discipline" by G. Camba-Mendez and A. Lamo, June 2002.

I53 "Euro area production function and potential output: a supply side system approach" by A. Willman, June 2002.

154 "The euro bloc, the dollar bloc and the yen bloc: how much monetary policy independence can exchange rate flexibility buy in an interdependent world?" by M. Fratzscher, June 2002.

155 "Youth unemployment in the OECD: demographic shifts, labour market institutions, and macroeconomic shocks" by J. F. Jimeno and D. Rodriguez-Palenzuela, June 2002.

156 "Identifying endogenous fiscal policy rules for macroeconomic models" by J. J. Perez, and P. Hiebert, July 2002.

157 "Bidding and performance in repo auctions: evidence from ECB open market operations" by K. G. Nyborg, U. Bindseil and I. A. Strebulaev, July 2002.

158 "Quantifying Embodied Technological Change” by P. Sakellaris and D. J. Wilson, July 2002.

159 “Optimal public money” by C. Monnet, July 2002.

160 "Model uncertainty and the equilibrium value of the real effective euro exchange rate" by C. Detken, A. Dieppe, J. Henry, C. Marin and F. Smets, July 2002.

16I "The optimal allocation of risks under prospect theory" by L. Stracca, July 2002.

162 "Public debt asymmetries: the effect on taxes and spending in the European Union" by S. Krogstrup, August 2002.

163 "The rationality of consumers' inflation expectations: survey-based evidence for the euro area" by M. Forsells and G. Kenny, August 2002.

164 "Euro area corporate debt securities market: first empirical evidence" by G. de Bondt, August 2002. 
165 "The industry effects of monetary policy in the euro area" by G. Peersman and F. Smets, August 2002.

166 "Monetary and fiscal policy interactions in a micro-founded model of a monetary union" by R. M.W.J. Beetsma and H. Jensen, August 2002.

167 "Identifying the effects of monetary policy shocks on exchange rates using high frequency data" by J. Faust, J.H. Rogers, E. Swanson and J.H. Wright, August 2002.

168 "Estimating the effects of fiscal policy in OECD countries" by R. Perotti, August 2002.

169 “Modeling model uncertainty” by A. Onatski and N. Williams, August 2002.

170 "What measure of inflation should a central bank target?" by G. Mankiw and R. Reis, August 2002.

I7I "An estimated stochastic dynamic general equilibrium model of the euro area" by F. Smets and R. Wouters, August 2002.

172 "Constructing quality-adjusted price indices: a comparison of hedonic and discrete choice models" by N. Jonker, September 2002.

173 "Openness and equilibrium determinacy under interest rate rules" by F. de Fiore and Z. Liu, September 2002.

174 "International monetary policy coordination and financial market integration" by A. Sutherland, September 2002.

175 "Monetary policy and the financial accelerator in a monetary union" by S. Gilchrist, J.O. Hairault and H. Kempf, September 2002.

176 "Macroeconomics of international price discrimination" by G. Corsetti and L. Dedola, September 2002.

177 "A theory of the currency denomination of international trade" by P. Bacchetta and E. van Wincoop, September 2002.

178 "Inflation persistence and optimal monetary policy in the euro area" by P. Benigno and J.D. López-Salido, September 2002.

179 "Optimal monetary policy with durable and non-durable goods" by C.J. Erceg and A.T. Levin, September 2002.

180 "Regional inflation in a currency union: fiscal policy vs. fundamentals" by M. Duarte and A.L. Wolman, September 2002.

18I "Inflation dynamics and international linkages: a model of the United States, the euro area and Japan" by G. Coenen and V. Wieland, September 2002.

182 "The information content of real-time output gap estimates, an application to the euro area” by G. Rünstler, September 2002. 
183 "Monetary policy in a world with different financial systems" by E. Faia, October 2002.

184 "Efficient pricing of large value interbank payment systems" by C. Holthausen and J.-C. Rochet, October 2002.

185 "European integration: what lessons for other regions? The case of Latin America" by E. Dorrucci, S. Firpo, M. Fratzscher and F. P. Mongelli, October 2002.

186 "Using money market rates to assess the alternatives of fixed vs. variable rate tenders: the lesson from 1989-1998 data for Germany” by M. Manna, October 2002.

187 “A fiscal theory of sovereign risk” by M. Uribe, October 2002.

188 “Should central banks really be flexible?" by H. P. Grüner, October 2002.

189 "Debt reduction and automatic stabilisation" by P. Hiebert, J. J. Pérez and M. Rostagno, October 2002.

190 "Monetary policy and the zero bound to interest rates: a review" by T. Yates, October 2002.

191 "The fiscal costs of financial instability revisited" by L. Schuknecht and F. Eschenbach, November 2002.

192 "Is the European Central Bank (and the United States Federal Reserve) predictable?" by G. Perez-Quiros and J. Sicilia, November 2002.

193 "Sustainability of public finances and automatic stabilisation under a rule of budgetary discipline” by J. Marín, November 2002.

194 "Sensitivity analysis of volatility: a new tool for risk management" by S. Manganelli, V. Ceci and W. Vecchiato, November 2002. 